\title{
Analysis of Failures of Pulpotomy Treated Primary Teeth: A Case Series and Review
}

\author{
Gajanan Kiran Kulkarni ${ }^{1}$, Mehmet Sinan Dogan², Ebru Akleyin ${ }^{3}$, Izzet Yavuz ${ }^{3}$ \\ 1 Pediatric and Preventive Dentistry, Faculty of Dentistry, University of Toronto. Toronto, Ontario, Canada. \\ 2Department of Pediatric Dentistry, Faculty of Dentistry, Harran University, Şanliurfa, Turkey. \\ 3Department of Pediatric Dentistry, Faculty of Dentistry, Dicle University, Diyarbakır, Turkey.
}

Received: January 10, 2021; Accepted: January 23, 2021; Published: January 28, 2021

“Corresponding author: Izzet YAVUZ, MSc, PhD, Professor, Pediatric Dentistry, Dicle Üniversity, Faculty of Dentistry 21280 Diyarbakir, TURKEY, E-mail: izzetyavuz@hotmail.com

\section{Abstract}

Objective: The aim of this study was to evaluate 6 extracted or exfoliated crowns of primary molars treated with different pulpotomy medicaments and techniques.

Materials and Methods: Six pulpotomy treated primary molars were examined whole and after bisection. The medicaments used in the study were formocresol, ferric sulfate. A few were primary teeth treated withlaser pulpotomies and mineral trioxide aggregate. Theteeth were either extracted due to clinical and/or radiographic failures. The reasons for failure or success were discerned with the radiographs and light microscopic inspection of different sections of the teeth

Results: Reasons for each failure could be determined by the above examinations. The primary reason for failure was determined to be clinical technique errors by the clinicians.

Conclusion: The success of pulpotomy is mostly dependent on the practical experience of the clinician, use of the appropriate materials and clinical technique.

Keywords: Primary Tooth; Pulpotomy; Failure.

\section{Introduction}

Today, pediatric endodontics focuses on preventing premature loss of the pulp of deciduous teeth up to physiological resorption in order to preserve the space between the teeth, prevent harmful language and speech habits, maintain aesthetics and maintain chewing function [1].

The ideal material to be placed on the radicular pulp should be bactericidal, should not damage the pulp and surrounding tissues, ensure the healing of the radicular pulp and not affect the physiological root resorption. For many years, researchers have searched for an ideal material to be left on pulp [2].

Although many materials and methods are used in the treatment of amputation, today there is no agent that has all the features of the ideal amputation material.Formocresol is the most commonly used material in the treatment of primary tooth amputation. However, there are doubts about the safety of formocresol due to its formaldehyde content [3]
Decayed primary teeth or the unsuccessful treatment of such teeth can lead to the development of sepsis $[4,5]$. In addition to these problems, the early loss of primary teeth can lead to problems such as shifting midline, malocclusions, permanent teeth remaining embedded, ectopic permanent teeth, and nutritional deficiences due to poor diets. Space maintainers which are used after the early loss of primary teeth, to reduce the above problems, have several disadvantages[4]. The maintenance of the primary tooth with restorative treatment is the best natural space maintainer for the succedaneous tooth. Different treatment methods and filling materials have been developed to treat extensive caries that involve the pulp[6]. One of these treatments is partial amputation of the affected pulp, in which the aim of treatment is to remove the coronal section of the pulp to preserve tooth vitality with the use of appropriate pulp preserving medicaments[7-10].

Correct diagnosis of the pulp status with clinical and radiographic examinations is one of the most important criteria in the success of pulp treatment ofprimary teeth. The aim of pulpotomy treatment in primary teeth is for the tooth to remain in the mouth until normal exfoliation by preserving the pulp vitality.Such treatment of primary teeth allows maintenance ofmasticatory function, and preserves arch space for normal growth and development of the dentition. [11].

Many materials have been used for the purpose of pulp fixation, protection or regeneration, including formocresol $[\mathrm{FC}]$, ferric sulfate, zinc oxide eugenol, Calcium Hydroxide [CH], Mineral Trioxide Agent [MTA], and Portland cement and Calcium Rich Mixture [CEM][7].

According to the mechanism of the action, materials can be classified into 3 groups:

1. Fixation using materials such as FC, electrosurgery and laser,

2. Protection with ferric sulphate and glutaraldehyde,

3. Regeneration with MTA and calcium hydroxide [10]. 
In addition to these materials, tricalcium phosphate, hydroxy apatite and bone morphogenetic protein have also been used. Following pulpotomy treatment, restoration can be made with a stainless steel crown, amalgam, composite or glass ionomer[12-14]. Forthe success of the treatment, the use of an appropriate restoration,that will prevent microleakage, is important [8]and is very dependent upon the clinician's skill and experience in placement of those restorationsStainless steel crowns are recommended as final restorations following pulpal treatment for long-term success [10].

In this study, weperformed clinico-pathologic evaluationof pulpotomy treated primary teeth along with their final restorations with the aim of corelating the success or failure of those treatments to the techniques employed.

\section{Materials and Methods}

The sample consisted of 6 primary molar teeth that had either exoliated naturally or were extracted following a pulpotomy and a final restoration. The materials used in the study were Formocresol [FC], and mineral trioxide aggregate [MTA] with laser, and composite, amalgam and stainless steel crowns were used as finishing restorations. The sample teth were extracted because of either clinical or radiographical failure. The specimens were first analysed intact, followed by examination of the same specimens which were sectioned mesio-distally. Specimens were inspected at 10X magnification under a dissecting microscope and photographed.

\section{Results}

In the first case,formocresol pulpotomy was performed and the tooth was restored with a distooccluals amalgam restoration. The treatmeant failed due to the development of a periapical lesion which extended into the furcation. External root resroption was noted at the apex of the distal rooth and internal resorption was noted in the mesial root. The tooth had to be extracted [Figure 1a]. From examination of cross-sections it was apparent that the coronal pulp had been removed appropriately. However, the Zinc Oxide Eugenol [ZOE] cement used to obturate the pulp chamber had extended well over the distal step of the preparation. Also there was significant overhang of the amalgam [Figures 1a, 1b]. The poor seal on the distal step of the restoration would have allowed ingress of plaque and bacteria into the remaining pulp tissue in the roots setting up a chronic inflammatory process. The cross-sectionsalso show that the pulp chamber had not been fully debrided of pulp tissue in the access preparation. This residulal pulp tissue would have necrosed and provided further incubation medium for anaerobic bacteria. [Figure $1 \mathrm{c}$ ].

In case no 2, a first primary molar was treated with FC pulpotomy andan amalgam restoration. The tooth had to be extracted due to the development of a periapical abscess. Examination of a radiograph of the extracted tooth [Figure 2a], the gross specimen [Figure 2b] and the bisected half [Figure 2c] revealed that the amalgam restoration was condensed into the pulp horns with little or no pulpotomy medicament overlying the amputed pulp stump. Moreover, the adaptation of the amalgam on the step portion of the preparation was rather poor. A clear area of carious dentin and a void can be clearly seen under the amalgam.[Figure 2c]. It is also apparent that the access to the pulp chamber had left overhanging tooth structure and pulp tissue which would have necrosed[Figure 2c].It is interesting to note that such an artefact would not be noticeable on a radiograph [Figure 2a].

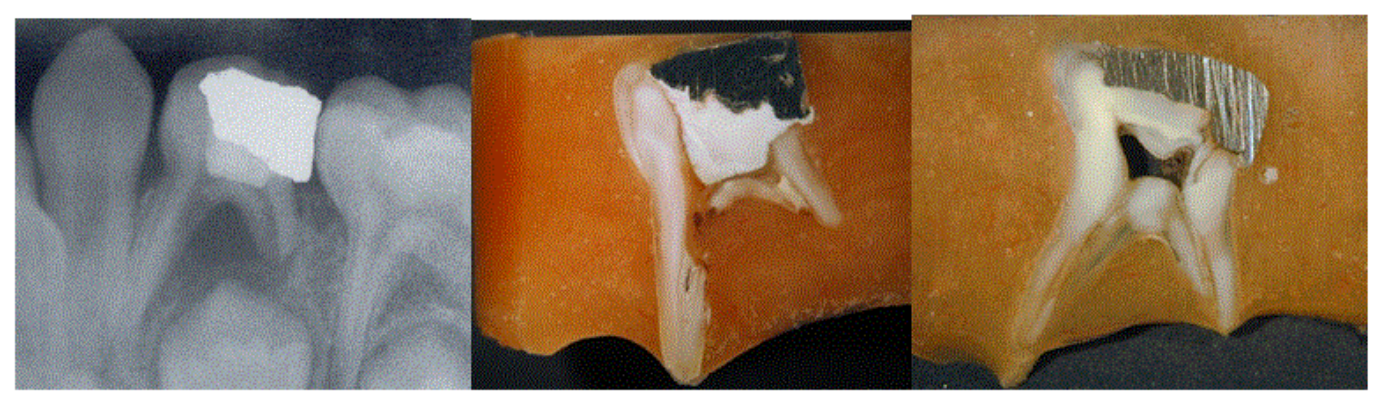

Figure 1 a, b, c: FC pulpotomy and amalgam restoration

Incase no 3 , a maxillary first primary molar was treated with FC pulpotomy and restored with a composite resin. The primary molar tooth had to be extracted due to a periapical abscess and premature root resporption. When the extracted tooth was examined, both the pulpotomy technique and restoration was seen to have major deficiencies [Figure $3 a, b, c]$. The sections reveal necrotic pulp in the pulp chamber and a very poorly adapted composite resin restoration. The inadequate preparation of the pulp chamber no doubt has prevented the complete removal of the pulp tissue and obturation of the pulp chamber with ZOE in one half of the pulp chamber [Figure 3b, c].Caries was seen on the proximal step[Figure 3b].

In case no. 4, pulpotomy was performed using a soft tissue laser followed with MTA obturation[15]. The final restoration was a 


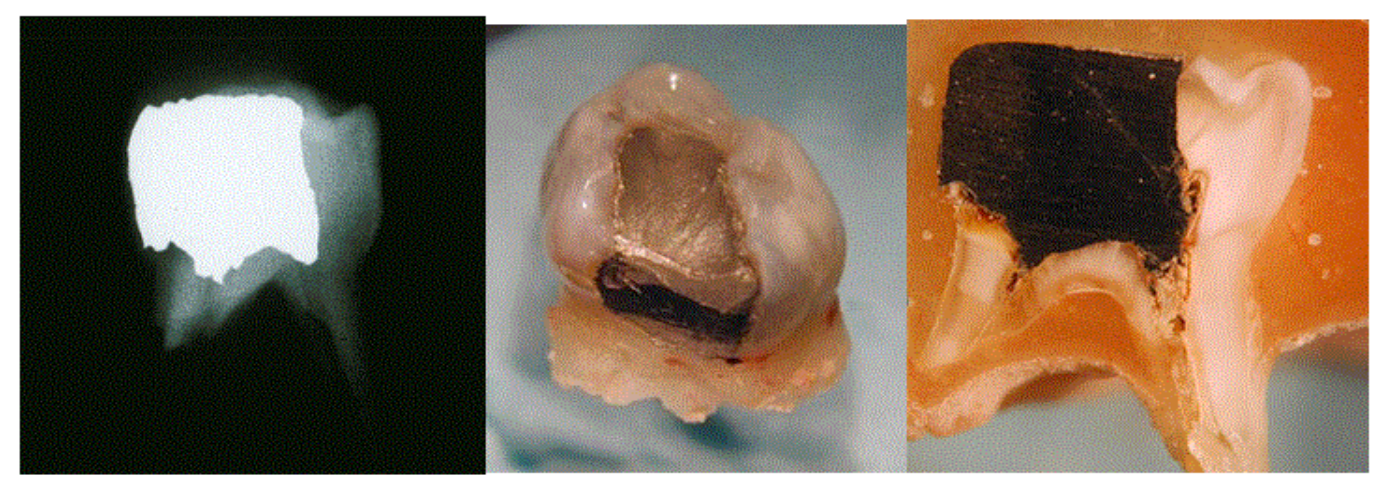

Figure $2 \mathbf{a}, \mathbf{b}, \mathbf{c}$ : $\mathrm{FC}$ amputation and amalgam restoration

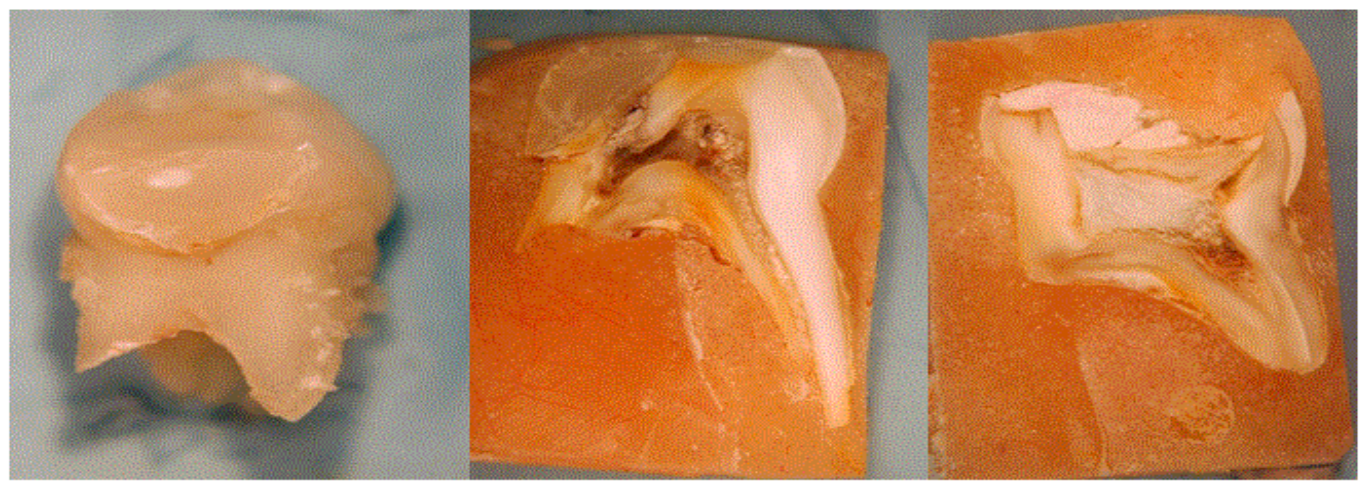

Figure 3 a, b, c: FC amputation and composite restoration

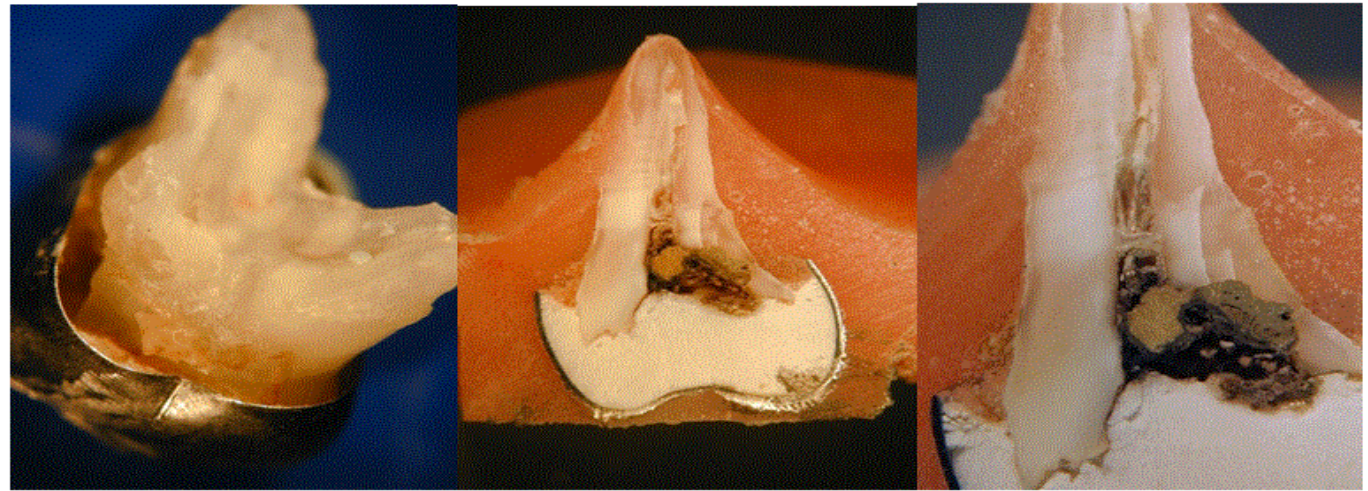

Figure 4 a, b, c: Laser MTA amputation and stainless steel restoration

stainless steel crown. Failure noted as a periapical lesion required extraction of the tooth. Examination of the gross specimens and the bisected halves of the tooth revealed a poorly adapted stainless steel crown that was too large for the tooth [Figures 4a, $\mathrm{b}, \mathrm{c}$. The poor adaptation also resulted in the loss of of the glass ionomer cement used to cement the crown. [Figure 4a].

In case no. 5, a FC pulptomy-SSC treated maxillary primary molar that had to be extracted due to a periapical abscess was analysed.
Examination of the the gross specimens [Figure 5a, b]reveal the premature resorption of the palatal root of the tooth and incomplete adaptation of the crown on the palatal aspect of the tooth. Much of the glass ionomer cement seems to have been lost where the crown is not well adapted to the tooth[Figures 5a, 5b]. Significantly, a pledget of cotton was seen in the pulp chamber below the ZOE pulpotomy medicament [Figure 5c].

In case no. 6, A mandibular second primary molar was treated 


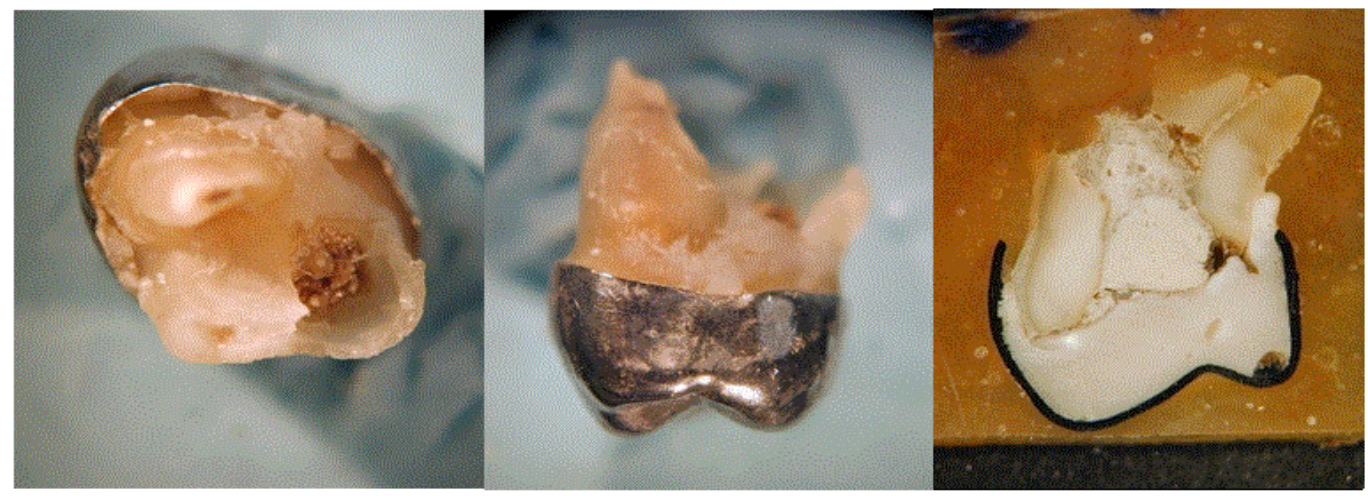

Figure 5 a, b, c: Maxillary first primary molar treated with FC pulpotomy and stainless steel crown

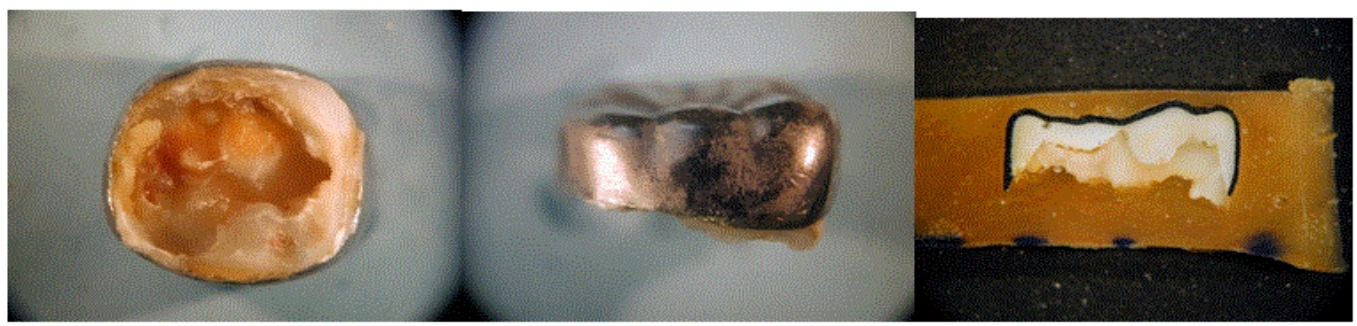

Figure 6 a, b, c: FC amputation and appropriately applied stainless steel crown

with FC pulpotomy and a SSC.The molar exfoliated naturally during the course of the child eating, The exfoliated tooth was analysed as above. Examination of the gross specimen revealed a good marginal adaption of the crown margins [Figure 6a]and uniform resorption of the roots [Figure 6b]. The bisected halves confirmed the good marginal seal and intact glass ionomer cement, right up to the crown margins [Figure 6c].

\section{Discussion}

Followingpulpotomy treatments in primary teeth, one or more clinical or radiological findings such as pain, inflammation, fistula pathway, periapical or inter-radicular radiolucency, or internal or external root resorption are signs of unsuccessful treatment. Several factors affect the success of pulpotomy treatments in primary molar teeth [7-10].

These include:

- Incomplete removal of coronal pulp from the access chamber

- Incomplete removal of carious tooth structure and the formation of secondary decay

- The presence of undiagnosed chronic periapical infection.

- The placement of tissue irritant materials such as ZOE in direct contact with the pulp tissue surface setting up a chronic inflammatory recation in the tissue.

- Infection caused by microleakage in fillings applied to teeth with extensive proximal decay.
Causes of failure associated with the final restorations used in pulp treatedprimary teeth have beeen determined as:

- Over- or under- fill of the restorative material.

- Poor seal between the restorative material and the tooth, particularly in the CEJ region.

- Poor adaptation of the stainless steel crown to the CEJ.

- Loss of the cement used as adhesive for the stainless steel crown.

Holan et.al., reported that the stainless steel crown was a more successful restorative finishing material than amalgam restorations in primary teeth treated with pulpotomy. Poor adaptation of stainless steel crowns or amalgam restorations particularly at the marginsmost often results in leakage and baterial penetration into the pulp [12].This is more so the case when composite resins are used as final restorations. The incomplete seal with composite resisn results from the incomplete cure of the resin if formocresol or eugenol is used in the pulpotomy treatment, and due to the shrinkage of the resin during curing. In case nos. 2, 3, 4, and 5 in the current study, the treatment was thought to have failed because of a gap and microleakage between the restoration and the tooth tissue [Figures 2-5].

It has been stated in dental literature that marginal microleakage has an effect on pulp inflammation. Poor adaptation of the margins of the restoration in pulp-treated teethhas been reported to be a reason for bacteria entering the pulp tissue and creating infection 
[12]. In case nos. 2, 3, 4, and 5 in the current study, on the stereo microscope [x25] images of the cross-sections obtained from the extracted teeth, microleakage of the restorations which did not have good border adaptation was seen to have caused the infections which were the reasons for extraction of the teeth [Figures 2-5]. The success rate of pulp-treated teeth isin part affected by the final restoration. In this respect, stainless steel crowns have been found to be superior to composite resins or glas ionomer restorations[Ketac Molar][16]. Stainless steel crowns have been reported to be more successful restorations compared to amalgam [14]. In restorations made after primary teeth amputation, the success rates of stainless steel crowns have been reported to be higher than those of composite and amalgam and in proximal surface restorations, amalgam has been reported to have a higher success rate than composite [13]. In case no 6 of the current study, the stainless steel crown restoration was seen to have good CEJ adaptation and was able to stay in the mouth until tooth root resorption was finished [Figure 6].In contrast, one study found that bulk-fill flowable composite with the sandwich technique was found to be as successful as stainless steel crowns [17]. But it must not be forgotten that because of anatomic changes such as the frequency and direction of the dental canals in the CEJ region in adhesive restorations, good bonding can not be made between the restoration and the dental tissue [18].

For pulpotomy treatment of primary teeth, MTA has been reported to be an effective agent [19-21]. In the current study, MTA was used in case no 4 and the finishing restoration was a stainless steel crown but the treatment was not successful. The treatment was thought to have failed because of poor adaptation of the stainless steel crown at the cervical margin[Figures $4 a, b$, c]. Well adapted stainless steel crowns that do not leak and are important in the success of amputation treatment [22; Figure 6].In this regard, both glass ionomer and polycarboxyl cementshave been reported to be equally successful as adhesive cements for stainless steel crowns. However, a greater rate of microleakage was reported with zinc phosphate cement [23]

In a retrospective study of amalgam and composite [Kompomer] restorations in primary teeth, the amalgam restorations were reported to be relatively more successful than the composite. A higher rate of microleakage and subsequent secondary decay was noted in the composite restorations. Fractures in the amalgam and composite restorations were also reported [24]. Case no 3 in our seriesa large void was noted between the composite resin restoration and the tooth in the step portion of the cavity at the CEJ. Active caries was also noted at the same location. In case nos 1 and 2,where restoration was made with amalgam, the reason for failure of the treatment was considered to be that as the pulp had not been completely cut and removed, it could not be filled and pulp had been left in the pulp chamber and then the amalgam restoration had overflowed [Figures 1,2].

In primary teeth which have lost a great amount of tooth material and are at risk of breakage, the success rates of stainless steel crowns is higher than that of other restorative materials [25]. In children with a high incidence of decay, the success rate of wide surface restorations has been stated to be low. The basic reasons for failure have been shown to be fracture of the restorations and the formation of secondary decay $[26,27]$. It has been reported that secondary decay occurs at a lower rate in amalgam restorations than in composite restorations [28]. The life of composite restorations in posterior teeth is shorter and there is a greater rate of formation of secondary decay compared to amalgam restorations [29]. The performance of amalgam in wide surface restorations has been reported to be better than that of composite [30].

In the current study, the teeth were seen to have a great amount of material loss and the restorations made were of a wide surface. The development of secondary decay was determined in the teeth restored with amalgam and composite. It can be considered that when a stainless steel crown has good adaptation to the CEJ, success can be obtained.

\section{Conclusion}

The success of pulpotomy treatments is affected as much by the pulpotomy agents as by the final restorations used,the practical techniques and the clinical experience of the clinician. Failures reasons for failures of pulp treated primary teeth include: The incomplete coronal pulp tissue removal and in particular the poor seal at the proximal step by the final restoration whether it be an amalgam, composite resin or a stainless steel crown restoration.

\section{References}

1. Junqueira MA, Cunha NNO, Caixeta FF, Marques NCT, Oliveira TM, et al. Clinical, radiographic and histological evaluation of primary teeth pulpotomy using MTA and ferric sulfate. Brazilian Dental Journal. 2018;29(2):159-165.

2. Coll JA, Seale NS, Vargas K, Marghalani AA, Al Shamali S, et al. Primary tooth vital pulp therapy: a systematic review and metaanalysis. Pediatric Dentistry. 2017;39(1):16-123.

3. Kaptan A, Çukurcu Ç. Current approaches to primary teeth amputation therapies. Turkiye Klinikleri Journal of Dental Sciences. 2020;26(1):122-312.

4. Finucane D. Rationale for restoration of carious primary teeth: a review. European Archives of Paediatric Dentistry. 2012;13(6):281292.

5. Pine CM, Harris RV, Burnside G, Merrett MCW. An investigation of the relationship between untreated decayed teeth and dental sepsis in 5-year-old children. British Dental Journal. 2006;200(1):45-47.

6. Qvist V, Poulsen A, Teglers PT, Mjör IA. The longevity of different restorations in primary teeth. International Journal of Paediatric Dentistry. 2010;20(1):1-7.

7. Shirvani A, Hassanizadeh R. Asgary S. Mineral trioxide aggregate vs. calcium hydroxide in primary molar pulpotomy: a systematic review. Iranian Endodontic Journal. 2014;9(2):83.

8. Jayam C, Mitra M, Mishra J, Bhattacharya B, Jana B. Evaluation and comparison of white mineral trioxide aggregate and formocresol 
medicaments in primary tooth pulpotomy: Clinical and radiographic study. Journal of Indian Society of Pedodontics and Preventive Dentistry. 2014;32(1):13.

9. Fares H, Nihal K. A new concept in conservatism Adult tooth pulpotomy: the promising success A nine years' study An evidence based study. Life Science Journal. 2014;11(6):276-282.

10. Lin PY, Chen HS, Wang YH, Tu YK. Primary molar pulpotomy: a systematic review and network meta-analysis. Journal of Dentistry. 2014;42(9):1060-1077.

11. Hincapié S, Fuks A, Mora I, Bautista G, Socarras F. Teaching and practical guidelines in pulp therapy in primary teeth in ColombiaSouth America. International Journal of Paediatric Dentistry. 2015;25(2):87-92.

12. Holan G, Fuks AB, Ketlz N. Success rate of formocresol pulpotomy in primary molars restored with stainless steel crown vs amalgam. Pediatr Dent. 2002;24(3):212-216.

13. Guelmann M, Mcllwain MF, Primosch RE. Radiographic assessment of primary molar pulpotomies restored with resin-based materials. Pediatric Dentistry. 2005;27(1):24-27.

14. Sonmez D, Duruturk L. Success rate of calcium hydroxide pulpotomy in primary molars restored with amalgam and stainless steel crowns. British Dental Journal. 2010;208(9):E18-E18.

15. Saltzman B, Sigal M, Clokie C, Rukavina J, Titley K, et al. Assessment of a novel alternative to conventional formocresol-zinc oxide eugenol pulpotomy for the treatment of pulpally involved human primary teeth: diode laser-mineral trioxide aggregate pulpotomy. International Journal of Paediatric Dentistry. 2005;15(6):437-447.

16. Guelmann M, Fair J, Bimstein E. Permanent versus temporary restorations after emergency pulpotomies in primary molars. Pediatric Dentistry. 2005;27(6):478-481.

17. Cantekin K, Gumus H. In vitro and clinical outcome of sandwich restorations with a bulk-fill flowable composite liner for pulpotomized primary teeth. Journal of Clinical Pediatric Dentistry. 2014;38(4):349354.

18. Santos GL, Beltrame APC, Triches TC, Filho M, Baptista D, et al. Analysis of microleakage of temporary restorative materials in primary teeth. Journal of Indian Society of Pedodontics and Preventive Dentistry. 2014;32(2):130.

19. Goyal P, Pandit IK, Gugnani N, Gupta M, Goel R, et al. Clinical and radiographic comparison of various medicaments used for pulpotomy in primary molars: A randomized clinical trial. European Journal of Dentistry. 2016;10(3):315.

20. Moretti ABS, Sakai VT, Oliveira TM, Fornetti APC, Santos CF, et al. The effectiveness of mineral trioxide aggregate, calcium hydroxide and formocresol for pulpotomies in primary teeth. International Endodontic Journal. 2008;41(7):547-555.

21. Gupta G, Rana V, Srivastava N, Chandna P. Laser Pulpotomy-an effective alternative to conventional techniques: a 12 months Clinicoradiographic study. International Journal of Clinical Pediatric Dentistry. 2015;8(1):18.

22. Guelmann M, Bookmyer KL, Villalta P, Godoy F. Microleakage of restorative techniques for pulpotomized primary molars. Journal of Dentistry for Children. 2004;71(3):209-211.

23. Mirkarimi M, Bargrizan M, Estiri M. The Microleakage of
Polycarboxylate, Glass Ionomer and Zinc Phosphate Cements for Stainless Steel Crowns of Pulpotomized Primary Molars. ZJMRS. 2013;15:6-9.

24. Soncini JA, Maserejian NN, Trachtenberg F, Tavares M, Hayes C. The longevity of amalgam versus compomer/composite restorations in posterior primary and permanent teeth: findings From the New England Children's Amalgam Trial. The Journal of the American Dental Association. 2007;138(6):763-772.

25. Attari N, Roberts JF. Restoration of primary teeth with crowns: a systematic review of the literature. European Archives of Paediatric Dentistry. 2006;1(2):58-62.

26. Wenckert IE, Folkesson UH, Dijken JW. Durability of a polyacidmodified composite resin (compomer) in primary molars: a multicenter study. Acta Odontologica Scandinavica. 1997;55(4):255260.

27. Opdam NJM, Sande FH, Bronkhorst E, Cenci MS, Bottenberg P, et al. Longevity of posterior composite restorations: a systematic review and meta-analysis. Journal of Dental Research. 2014;93(10):943-949.

28. Levin L, Coval M, Geiger SB. Cross-sectional radiographic survey of amalgam and resin-based composite posterior restorations. Quintessence International. 2007;38(6).

29. Moraschini V, Fai CK, Alto RM, Santos GO. Amalgam and resin composite longevity of posterior restorations: A systematic review and meta-analysis. Journal of Dentistry. 2015;43(9):1043-1050.

30. Bernardo M, Luis H, Martin MD, Leroux BG, Rue T, et al. Survival and reasons for failure of amalgam versus composite posterior restorations placed in a randomized clinical trial. The Journal of the American Dental Association. 2007;138(6):775-783. 